\title{
DESEMPENHO DE DUAS CULTIVARES DE CHICÓRIA EM TRÊS AMBIENTES DE CULTIVO
}

\author{
Performance of two endive (Cichorium endivia L.) cultivars under three environments
}

\author{
Guilherme Domingues de Sá1, Marie Yamamoto Reghin²
}

\begin{abstract}
RESUMO
Pelo crescente aumento da importância econômica e perante a escassez de informações técnicas para o cultivo da chicória (Cichorium endivia L.), objetivou-se com o presente trabalho avaliar o comportamento de duas cultivares em três ambientes de cultivo, no período de 11/09/04 a 04/12/04, em Ponta Grossa (PR). Os tratamentos foram arranjados em parcela subdividida, constituindo-se a parcela em ambientes de cultivo (túnel baixo, agrotêxtil branco e ambiente natural) e a subparcela em cultivares (AF254 e Marina). O delineamento experimental foi o de blocos casualizados, com quatro repetições. As mudas foram produzidas sob ambiente protegido, em bandejas de poliestireno, com o substrato Plantmax e transplantadas aos 39 dias da semeadura. Após o transplante, foram instalados o túnel baixo coberto com polietileno e o agrotêxtil branco de $17 \mathrm{~g} \cdot \mathrm{m}^{-2}$. Na colheita, foram avaliados a ocorrência de tipburn, número de folhas por planta e massa fresca da planta. Observou-se que os maiores valores de temperaturas máximas e mínimas foram encontrados sob agrotêxtil, até 20 dias após o transplante e, posteriormente, com o desenvolvimento das plantas, os valores ficaram muito próximos entre os três ambientes. O ambiente que propiciou maior rendimento em massa fresca da cabeça foi o túnel baixo. Dentre cultivares, AF-254 apresentou melhor desempenho que Marina, tendo superioridade na massa fresca, embora tenha apresentado maior suscetibilidade a tipburn, quando em ambiente protegido.
\end{abstract}

Termos para indexação: Cichorium endivia, desempenho de cultivares, túnel baixo, polipropileno.

\begin{abstract}
Considering the increasing of economical importance on endive and the need of studies on this crop, the present work aimed to evaluate the behaviour of two endive cultivars (Cichorium endivia L.) under differents ambients during the period from 11/09/04 to 04/12/04, in Ponta Grossa, Paraná State. The experimental outline was a randomized block with the treatments arranged in a split plot, with four replications, being the plots represented by crop ambients (low tunnel of polyetylene, polypropylene as floating cover and natural ambient), and two cultivars (AF-254 and Marina). Endive seedlings were produced under protected cultivation, on polyestyrene trays with 200 cells, with the substrate Plantmax ${ }^{\circledR}$. The seedlings were tranplanted at open field, 39 days after sowing. After seedling transplanting, the low tunnel was installed and also the white polypropylene with $17 \mathrm{~g} . \mathrm{m}^{-2}$. At plant harvest, it was evaluated the number of leaves, head fresh weight and the incidence of Tipburn. The highest values of maximum and minimum temperature were observed under polypropylene till 20 days after transplant. According to the plants development the values of temperature became very close among the ambients. The highest head fresh weight was obtained at ambient of low tunnel. Between cultivars, AF-254 showed better performance than Marina, being superior on head fresh weight, although the first cultivar was more suscetible to Tipburn under protected cultivation.
\end{abstract}

Index terms: Cichorium endivia, cultivar performance, low tunnel, polypropylene.

(Recebido em 30 de novembro de 2006 e aprovado 19 de julho de 2007)

\section{INTRODUÇÃO}

A chicória (Cichorium endivia L.) é uma planta que tem sua origem na Índia Oriental e é conhecida e utilizada na alimentação humana desde o Egito antigo, na forma cozida ou como salada. Existem duas variedades claramente definidas que são Cichorium endivia var. crispa L., que é a chicória crespa, caracterizada pelas folhas bastante recortadas, e Cichorium endivia var. latifolia L., variedade lisa que tem no Brasil o maior consumo e valor comercial (FILGUEIRA, 2000).
A chicória produz melhor sob temperaturas amenas, embora havendo cultivares tolerantes a temperaturas mais elevadas. Geralmente a semeadura ocorre no outonoinverno, porém pode-se cultivar ao longo do ano, em regiões de altitude (FILGUEIRA, 2003).

Segundo Camargo Filho \& Mazzei (2001), a época de maiores preços alcançados na CEAGESP pela chicória ocorre entre novembro a abril, período em que a elevação da temperatura e o aumento nos índices pluviométricos dificultam o desenvolvimento de hortaliças folhosas com conseqüente redução na oferta e elevação dos preços.

\footnotetext{
${ }^{1}$ Mestre - Departamento de Fitotecnia e Fitossanidade/DEFITO - Universidade Estadual de Ponta Grossa/UEPG - Avenida Carlos Cavalcanti, 4748 Uvaranas - 84030-900 - Ponta Grossa, PR - guile-agro@hotmail.com - Bolsista da CAPES

2Doutora, Professora Adjunto - Departamento de Fitotecnia e Fitossanidade/DEFITO - Universidade Estadual de Ponta Grossa/UEPG - Avenida Carlos Cavalcanti, 4748 - Uvaranas - 84030-900 - Ponta Grossa, PR - freghin@convoy.com.br
} 
Comportamento semelhante é verificado no Estado do Paraná, onde, segundo dados da CEASA-PR (2004), os maiores volumes comercializados de chicória encontramse entre maio e outubro (média dos últimos 5 anos), época de preços mais baixos e os menores volumes são de novembro a abril com maiores preços.

Um dos maiores desafios para o produtor de folhosas é manter a regularidade de comercialização, pois o cultivo é constantemente prejudicado por adversidades climáticas, dentre elas, a ocorrência de chuvas pesadas que provoca danos nas folhas e diminui a qualidade do produto, prolonga o ciclo da planta e atrasa a época prevista de colheita.

Na Europa, grande parte da chicória é cultivada sob cultivo protegido, em túneis ou coberturas flutuantes de agrotêxtil (MAROTO, 1995). Os túneis baixos são utilizados principalmente em espécies de pequeno porte. Apresenta vantagens como a ampliação do período de produção, através do cultivo em épocas em que a temperatura do ar no ambiente externo não favorece ou inviabiliza o seu cultivo, com obtenção de produtos de melhor qualidade (ROBLEDO \& MARTIN, 1981).

No final da década de 90, Otto et al. (2001) iniciaram estudos no Paraná com o agrotêxtil branco, quando em alface (Lactuca sativa L.) observaram precocidade de produção e aumento de produtividade. Desde então, vários trabalhos foram desenvolvidos em diversas hortaliças, tendo respostas positivas em morango (Fragaria ananassa Duchesne) (OTTO et al., 2000), rúcula (Eruca sativa Mill.) (REGHIN et al., 2002a); pak choi (Brassica chinensis L.) (REGHIN et al., 2002b) e alface (BARROS JUNIOR et al., 2004). No Brasil, estima-se que quase a totalidade do cultivo seja realizado em ambiente natural.

Como na literatura consultada não se encontraram resultados experimentais de chicória sob cultivo protegido, conduziu-se este trabalho com o objetivo de avaliar as respostas produtivas de duas cultivares de chicória lisa cultivadas sob túnel baixo, agrotêxtil branco e ambiente natural.

\section{MATERIAL E MÉTODOS}

O trabalho foi conduzido em Ponta Grossa, no período de 11/09 a 4/12 de 2004, na Universidade Estadual de Ponta Grossa, com altitude média de 900 m. A pluviosidade média anual é de $1422 \mathrm{~mm}$, sendo janeiro o mês mais chuvoso e agosto o mês que apresenta menores precipitações. A umidade relativa do ar média anual fica em torno de $75 \%$ (GODOY et al., 1976). O solo da área experimental foi classificado como Cambissolo distrófico de textura argilosa. $\mathrm{O}$ delineamento experimental utilizado foi o de blocos ao acaso, com quatro repetições, sendo os tratamentos arranjados em parcelas subdivididas, em que a parcela era representada pelos ambientes (natural, túnel baixo e agrotêxtil branco) e a subparcela pelas cultivares (Marina e AF-254).

A produção de mudas foi realizada sob ambiente protegido, em estrutura de arcos e coberto com filme de polietileno de 120 micras, com semeadura feita em bandejas de poliestireno expandido de 200 células, contendo substrato Plantmax-HT, em 11/09/2004. O transplante ocorreu 39 dias após a semeadura, quando as mudas apresentavam quatro folhas definitivas. Utilizou-se o espaçamento de $0,30 \times 0,30 \mathrm{~m}$, em parcelas de $0,90 \mathrm{~m}$ de largura por 4,20 m de comprimento totalizando 42 plantas por parcela. A adubação foi realizada com base na análise química de solo, segundo Katayama (1993), utilizando-se $120 \mathrm{~g} / \mathrm{m}^{2}$ da formulação 02-25-25, e a adubação de cobertura efetuada aos 15 dias com uréia, com uma dose de $5 \mathrm{~g} /$ planta.

A montagem da estrutura do túnel baixo e a colocação do agrotêxtil foram realizadas após o transplante (DAT) das mudas. O túnel baixo foi constituído por arcos de tubos de PVC de 1/2 polegada de diâmetro e 2,0 metros de comprimento, os quais foram enterrados $30 \mathrm{~cm}$ de cada extremidade nas laterais do canteiro, espaçados de 1,00 m. A altura no ponto central foi de $1,00 \mathrm{~m}$ da superfície do solo. Para a cobertura do túnel foi utilizado filme de polietileno com 100 micras de espessura e 2,00 metros de largura com tratamento anti UV. O filme foi fixado com o auxílio de fitilhos de polietileno, fixados ao chão com o auxílio de grampos de ferro e cruzados sobre os arcos. As laterais do túnel foram mantidas com abertura de $20 \mathrm{~cm}$ durante todo o ciclo da cultura. $\mathrm{O}$ agrotêxtil branco, com densidade de $17 \mathrm{~g} . \mathrm{m}^{-2}$, foi colocado sobre arcos para a sustentação do material. Os arcos foram feitos de ferro tubular com 5/16 de diâmetro fixado, ao solo da mesma forma que o arco de PVC, porém a forma do arco foi de "U" invertido, ficando com altura fixa de $0,30 \mathrm{~m}$ no centro e nas bordas do canteiro, a partir da superfície do solo. Os arcos foram espaçados em 2,00 m .

Para a irrigação montaram-se duas linhas de tubo gotejador com emissores espaçados em $0,30 \mathrm{~m}$ e vazão de 1,5 L.h ${ }^{-1}$. Quando da ocorrência de chuvas, a irrigação somente era realizada nas parcelas protegidas pelo túnel. O controle das plantas infestantes foi realizado manualmente aos 27 e 40 DAT.

Em cada um dos ambientes de cultivo (túnel baixo, agrotêxtil e ambiente natural), foram monitorados alguns parâmetros microclimáticos, por meio de sensores acoplados a um sistema de aquisição de dados (Datalogger 
CR23x). O equipamento foi programado para realizar leituras a cada minuto, armazenando somente a média horária das 60 leituras, sendo 1 sensor de radiação solar modelo LI 190SB Li-Cor Quantum Sensor, instalado a 0,30 m de altura da superfície do solo; 1 sensor de temperatura modelo 107 Temperature probe, instalado a $10 \mathrm{~cm}$ de altura do solo para leitura da temperatura do ar.

$\mathrm{Na}$ colheita, aos $45 \mathrm{DAT}$, foram avaliadas o número de folhas (considerando aquelas que apresentavam comprimento superior a $20 \mathrm{~mm}$ ), a massa fresca e a ocorrência de tipburn (distúrbio fisiológico) através da contagem do número total de plantas por parcela com sintoma do distúrbio.

Os resultados foram submetidos à análise de variância e nos casos de significância, usou-se teste de Tukey no nível de 5\% para comparação das médias.

\section{RESULTADOS E DISCUSSÃO}

A partir dos 31 dias após o transplante foram observados os primeiros sintomas de tipburn na planta. Segundo Saure (1998), tipburn é uma necrose nas margens das folhas jovens em desenvolvimento, na parte interna da cabeça. Essa desordem fisiológica pode causar perdas econômicas sérias. A deficiência de cálcio é freqüentemente considerada como a causa principal, e fatores externos como temperatura, luz, umidade e solo apresentam relações com o distúrbio.

$\mathrm{Na}$ colheita, os valores observados de tipburn apresentaram interação significativa. A cultivar AF-254 apresentou maior percentual de plantas com tipburn em relação à Marina, quando em cultivo protegido (túnel e agrotêxtil) mas os percentuais foram semelhantes no ambiente natural (Tabela 1). Na cultivar Marina não houve efeito significativo dos ambientes, enquanto na AF-254 o túnel favoreceu o aparecimento do distúrbio. Collier \& Huntington (1983) e Saure (1998), citam que a suscetibilidade a tipburn é determinada geneticamente, mas influenciada pelo ambiente tanto por fatores que promovem o crescimento exuberante como os que, paradoxalmente, reduzem seu crescimento.

Isto explica o comportamento diferenciado entre as cultivares e também a influência do túnel sobre AF-254, ambiente que propiciou crescimento maior e mais acelerado das plantas. Desse modo, o fornecimento de cálcio para os pontos de crescimento não acompanha a velocidade de crescimento celular. Embora tenha apresentado maior suscetibidade que Marina à ocorrência de tipburn, deve ser destacado a alta qualidade de AF-254, com folhas de coloração verde-clara e muito tenras. Essa cultivar ainda não é comercial e, portanto, sem descrição publicada pela empresa. No experimento, observou-se que é um genótipo de porte grande e coração cheio. As folhas são compridas, lisas e mais recortadas que a cultivar comercial Marina.

Os valores observados para número de folhas por planta apresentaram interação significativa e para massa fresca da planta, houve significância dos fatores de forma isolada (Tabela 2). A cultivar AF-254 apresentou maior média de folhas comparada à Marina, quando cultivada em ambiente natural. Entre ambientes, os maiores valores foram encontrados sob túnel e natural para AF-254 e no túnel para Marina. Embora AF-254 tenha apresentado igual número de folhas sob ambiente natural e túnel, as folhas sob ambiente natural não apresentaram igual desenvolvimento às observadas sob túnel (Tabela 2).

Os valores médios de massa fresca demonstram que independentemente do ambiente e da cultivar, as cabeças produzidas foram volumosas e com massa acima de $350 \mathrm{~g}$, o que é altamente favorável (Tabela 2). O tamanho da planta é um atributo comercial importante, considerando que a chicória é comercializada nos mercados atacadistas em engradados. Dessa forma, quanto maior o tamanho, tanto menor será o número necessário para completar o engradado. Entre as cultivares, AF-254 apresentou maiores valores para massa fresca, diferindo significativamente em relação à Marina (Tabela 2). Cabe ressaltar que as plantas provenientes de cultivo protegido, as folhas apresentavamse mais tenras e limpas principalmente as da cultivar AF-

Tabela 1 - Percentual de plantas com sintoma de Tipburn aos 45 DAT, observadas nas cultivares AF-254 e Marina em função do ambiente de cultivo. Ponta Grossa (Pr). 2004.

\begin{tabular}{|c|c|c|}
\hline Ambiente & AF-254 & Marina \\
\hline Túnel & $40,4 \mathrm{~A}$ a & $33,4 \mathrm{~B}$ a \\
\hline Agrotêxtil & $34,3 \mathrm{~A} \mathrm{~b}$ & $33,2 \mathrm{~B} \mathrm{a}$ \\
\hline Natural & $33,2 \mathrm{~A} \mathrm{~b}$ & $33,2 \mathrm{~A} \mathrm{a}$ \\
\hline
\end{tabular}

*Médias seguidas da mesma letra maiúscula na linha e minúscula na coluna não diferem significativamente entre si no nível de 5\% de probabilidade pelo teste de Tukey. Dados transformados em arc sen "( $x+a$ alfa) 100 . 
Tabela 2 - Número de folhas e massa fresca de cultivares de chicória aos 45 dias do transplante, em função do ambiente de cultivo. Ponta Grossa (PR). 2004.

\begin{tabular}{llcccc}
\hline & \multicolumn{2}{l}{ Número de folhas por planta } & \multicolumn{3}{c}{ Massa fresca $\left(\mathrm{g} \cdot \mathrm{planta}^{-1}\right.$ ) } \\
\hline Ambiente & AF-254 & Marina & AF-254 & Marina & Média \\
\hline Túnel & $51,6 \mathrm{~A}^{*} \mathrm{a}^{*}$ & $50,6 \mathrm{~A} \mathrm{a}$ & 494,5 & 452,3 & $473,4 \mathrm{a}^{*}$ \\
Agrotêxtil & $45,2 \mathrm{~A} \mathrm{~b}$ & $44,6 \mathrm{~A} \mathrm{~b}$ & 348,4 & 362,0 & $355,2 \mathrm{~b}$ \\
Natural & $52,0 \mathrm{~A} \mathrm{a}$ & $42,8 \mathrm{~B} \mathrm{~b}$ & 376,8 & 347,9 & $362,4 \mathrm{~b}$ \\
\hline Média & 49,6 & 46,0 & $406,6 \mathrm{~A}$ & $387,4 \mathrm{~B}$ & \\
\hline
\end{tabular}

*Médias seguidas da mesma letra maiúscula na linha e minúscula na coluna não diferem significativamente entre si no nível de 5\% de probabilidade pelo teste de Tukey.

254, fato de extrema importância, pois cultivares comerciais como Marina ainda apresentam folhas mais duras e rústicas.

Dentre ambientes, o que propiciou maior massa fresca foi o túnel, tendo acréscimos de $25 \%$ em relação ao agrotêxtil e de 23,4\% em relação ao ambiente natural (Tabela 2). Esta superioridade do túnel em relação ao ambiente natural concorda com resultados obtidos por Streck et al. (1994) em alface e Reghin et al. (2001) com alface americana.

Benoit \& Ceustermans (1987) com a chicória desenvolvida na primavera, comparadas no agrotêxtil e em túneis plásticos perfurados, obtiveram os menores valores de massa fresca na colheita para o tratamento com agrotêxtil. Concluíram que o resultado pode ser em função da grande permeabilidade do material em relação ao plástico, promovendo transpiração excessiva da planta e também à menor transmissão de radiação, 59\% contra $61 \mathrm{e}$ $69 \%$ dos materiais plásticos, proporcionando menor ganho de massa fresca. Conforme os autores, a perda de peso causada pelo incremento na transpiração foi cerca de $20 \%$ maior que a perda causada pela redução da luminosidade.

As temperaturas máximas (Figura 1) e mínimas (Figura 2) do ar sob agrotêxtil foram maiores que em ambiente natural e túnel durante todo o ciclo da cultura. $\mathrm{O}$ ambiente sob agrotêxtil apresentou temperaturas mínimas superiores aos demais tratamentos, porém com diferenças muito pequenas em relação a estes. A temperatura mínima do ar atingiu valores baixos logo após o transplante (em torno de $9^{\circ} \mathrm{C}$ ), entre 9 a 15 dias (em torno de $8^{\circ} \mathrm{C}$ ) e entre 26 a 30 dias (em torno de $8{ }^{\circ} \mathrm{C}$ ), o que contribuiu para a ampliação do período vegetativo da cultura para 84 dias, pois conforme a empresa mantenedora dos genótipos, o início da colheita ocorre 60 a 70 dias após a semeadura.

Por outro lado, no ambiente sob agrotêxtil, foram observadas temperaturas máximas muito elevadas, acima de $40^{\circ} \mathrm{C}$, até 20 dias após o transplante. Observou-se redução dessas, de acordo com o desenvolvimento das plantas, porém apresentaram nova elevação aos 37 dias.
As altas temperaturas influenciam negativamente o desenvolvimento das plantas pela aceleração excessiva no metabolismo da planta que passa a consumir mais energia com conseqüiente redução no acúmulo de massa. A diferença entre as temperaturas máximas diminuíram com o desenvolvimento das plantas e a partir dos 37 dias após o transplante, ficaram muito próximas entre os três ambientes de cultivo. A mesma resposta foi observada por Pereira et al. (2003), quando comparou o ambiente sob agrotêxtil com o natural, em feijão-vagem. Isto ocorre pela mudança no balanço de energia dentro do ambiente de cultivo. Esta mudança é influenciada principalmente pelo desenvolvimento das plantas que passam a absorver muita radiação para o processo fotossintético e esta radiação não mais se transforma em calor dentro do ambiente de cultivo.

Em relação à radiação solar PAR, foi realizada uma análise em dois casos distintos, cujos dados são apresentados nas Figuras 3 e 4. Na Figura 3 é apresentado o comportamento da radiação solar nos três ambientes de cultivo em um dia com alta radiação solar. $\mathrm{O}$ pico de radiação ocorre às 12 horas e o ambiente natural apresenta os maiores valores de radiação solar PAR (fotossinteticamente ativa). Ao longo do dia, verifica-se que os valores de radiação começam a se elevar às 7 horas e, a partir das 14 horas, entram em declínio até às 19 horas quando chegam ao ponto zero de radiação solar com o total pôr-do-sol. A diferença verificada entre os ambientes protegidos e o natural é que sempre o ambiente natural apresenta valores superiores a qualquer um dos ambientes protegidos, porém a radiação no túnel por várias vezes ao dia está muito próxima aos valores do ambiente natural e, quando estas diferenças são acumuladas durante o dia, chega-se a um valor de transmissividade de radiação PAR incidente de 90,7\% para o túnel em relação ao ambiente natural. No agrotêxtil, os valores se apresentam com $73,9 \%$ da radiação PAR, bem abaixo do túnel. 
Estes valores de transmissividade para o túnel concordam com Ricieri \& Escobedo (1996) que chegaram a valores de $91,6 \%$. Os valores encontrados para o agrotêxtil ficaram próximos aos encontrados por Okimura \& Hanada (1993), que citam transmissividade de 65 a $70 \%$ no verão, e também por Otto (1997) com valores de 65 a 85\%.

Em uma outra situação (Figura 4) é representada a radiação PAR incidente sobre os ambientes em um dia de baixa radiação, dia este que iniciou com radiação em elevação e, por volta das 8 horas, os valores entraram em declínio em função de o tempo ficar nublado com posterior chuva. A partir das 14 horas, o tempo voltou a abrir, e as taxas de radiação tiveram ligeiro aumento com posterior queda em função do pôr-do-sol. Neste caso, nota-se que a diferença entre os ambientes ficou ainda maior sendo que o túnel ficou com valor de transmissividade de 87,9\%, concordando com Ricieri \& Escobedo (1996), que chegaram a valores de $87,3 \%$ e o agrotêxtil de $67,6 \%$, concordando com Okimura \& Hanada (1993).

Esta maior quebra de radiação proporcionada pelo agrotêxtil pode limitar a atividade da planta, a qual pode não atingir o seu ponto de saturação fotossintético, que para a maioria dos cultivos hortícolas situa-se ao redor de $1200 \mu \mathrm{mol} . \mathrm{m}^{-2} . \mathrm{s}^{-1}$ (WOLFE, 1979, citado por OTTO, 1997) e com isso reduzir a produção de fotoassimilados com possível redução de produção final.

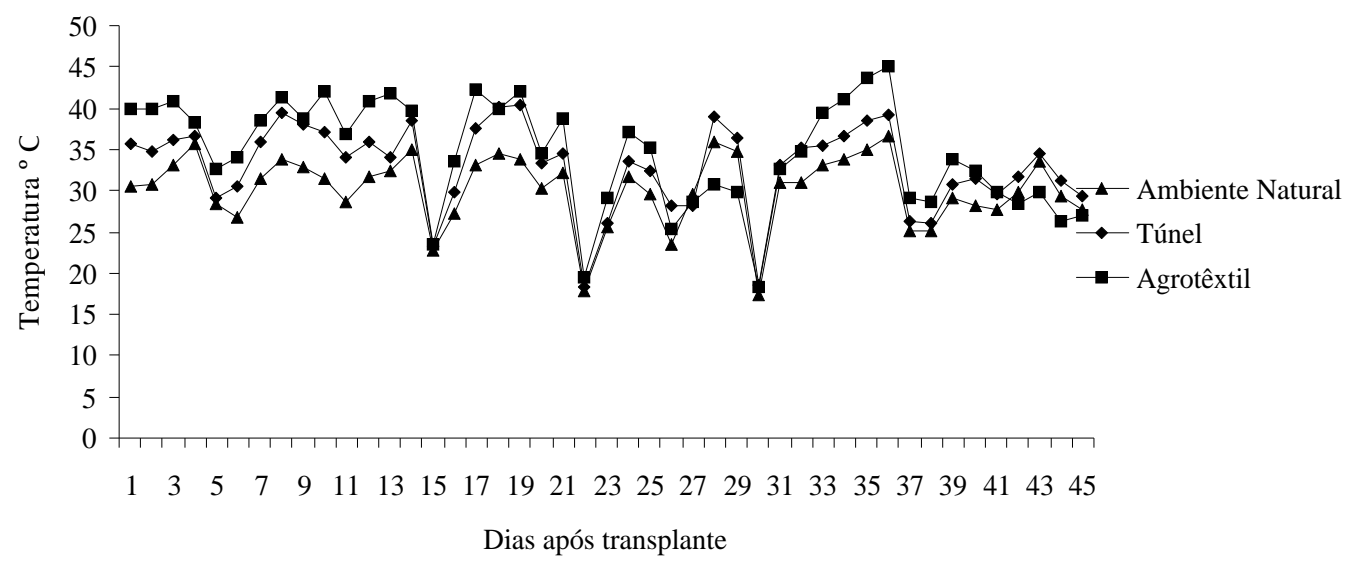

Figura 1 - Temperatura máxima do ar (10 cm de altura do solo) em três sistemas de cultivo, durante o ciclo vegetativo da chicória. Ponta Grossa (PR). 2004.

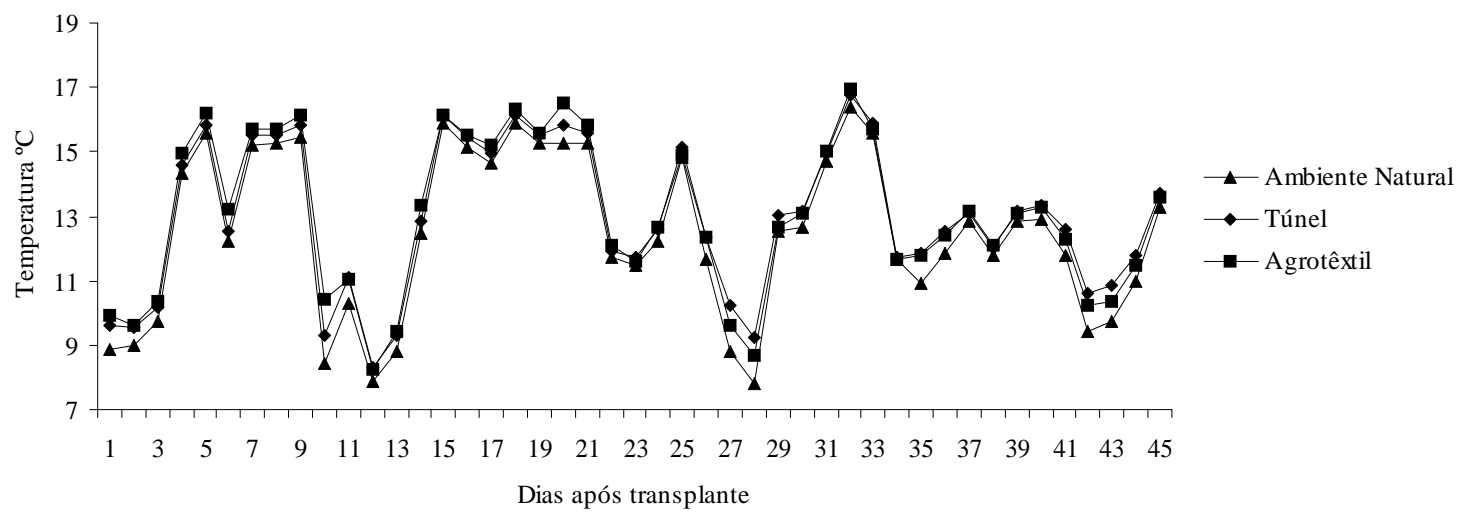

Figura 2 - 'lemperatura mínima do ar $(10 \mathrm{~cm}$ de altura do solo $)$ em três sistemas de cultivo, durante o ciclo vegetativo da chicória. Ponta Grossa (PR). 2004. 


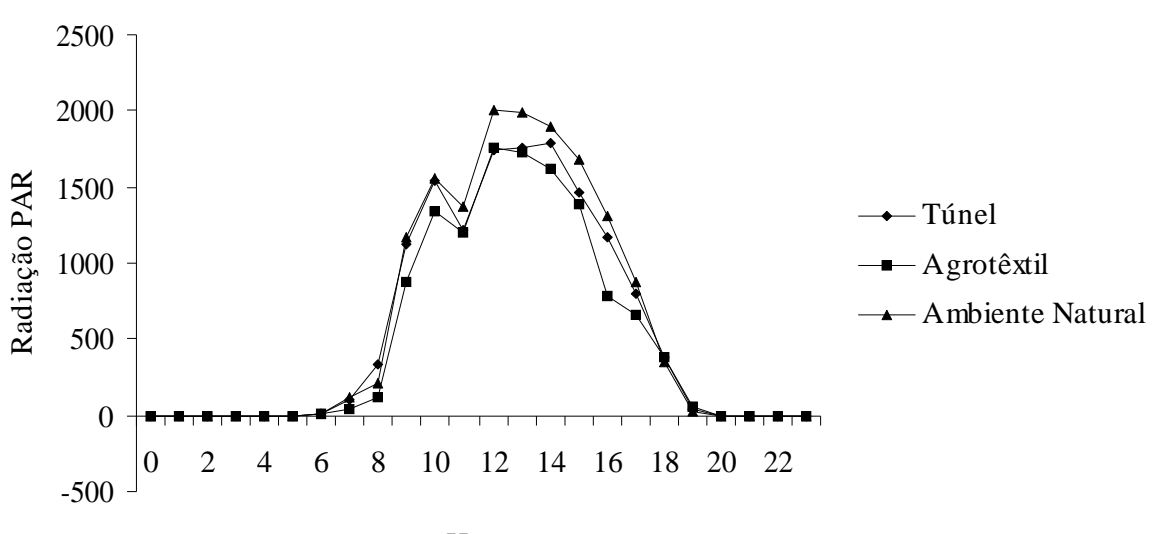

Figura 3 - Evolução da radiação solar PAR $\left(\mu \mathrm{mol} . \mathrm{m}^{-2} \cdot \mathrm{s}^{-1}\right)$ em três ambientes de cultivo em um dia com alta radiação solar. Ponta Grossa (PR). 2004.

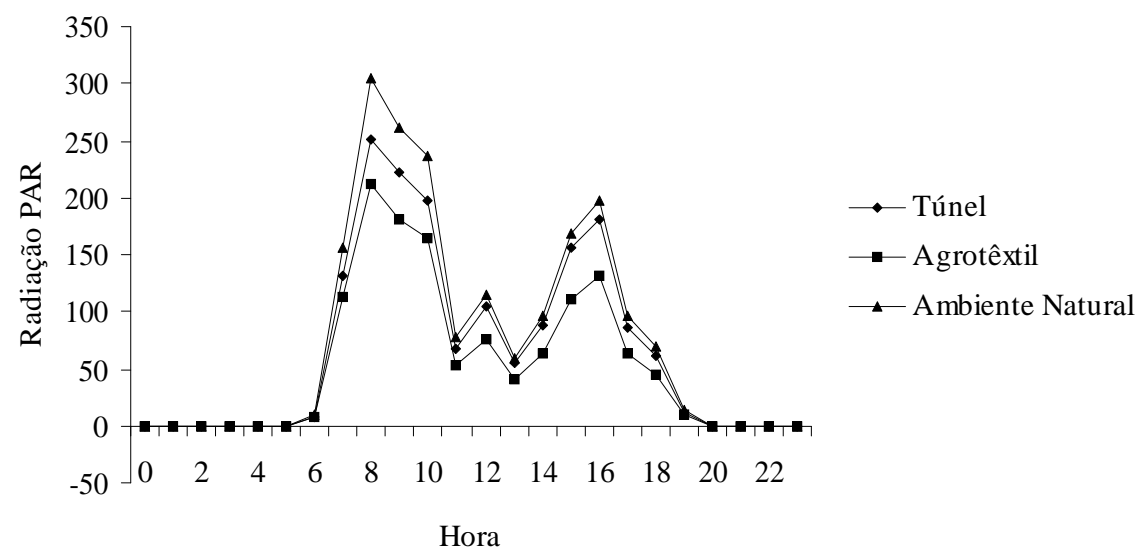

Figura 4 - Evolução da radiação solar PAR $\left(\mu \mathrm{mol} . \mathrm{m}^{-2} \cdot \mathrm{s}^{-1}\right)$ em três ambientes de cultivo em um dia com baixa radiação solar. Ponta Grossa (PR). 2004.

\section{CONCLUSÕES}

Nas condições em que foi conduzido o experimento conclui-se que a cultivar AF-254 foi mais produtiva que Marina;

O túnel foi melhor para o cultivo de chicória, se a comercialização for em termos de massa, mas, se for em número, então, o melhor foi o cultivo natural.

\section{REFERÊNCIAS BIBLIOGRÁFICAS}

BARROS JUNIOR, A. P.; GRANGEIRO, L. C.; BEZERRA NETO, F.; NEGREIROS, M. Z.; SOUZA, J. O.; AZEVEDO, P. E.; MEDEIROS, D. C. Cultivo da alface em túneis baixos de agrotêxtil. Horticultura Brasileira, Brasília, v. 22, n. 4, p. 801-803, out./dez. 2004.

BENOIT, F.; CEUSTERMANS, N. Advancing the harvest of bolt-sensitive endive (Cichorium endivia L.) by means of temporary single and double direct crop covering (DC). Acta Horticulturae, Leuven, n. 198, p. 269-275, 1987.

CAMARGO FILHO, W. P. de; MAZZEI, A. R. Mercado de verduras: planejamento e estratégia na comercialização. Informações Econômicas, São Paulo, v. 31, n. 3, mar. 2001.

CEASA-PR. Evolução da comercialização e de preços de chicória na Ceasa Paraná. Disponível em: <http// celepar7.pr.gov.br/cesa/cotações/html>. Acesso em: 17 nov. 2004.

COLLIER, G. F; HUNTINGTON, V. C. The relationship between leaf growth, calcium accumulation and distribution, and tipburn development in field-grown butterhead lettuce. Scientia Horticulturae, Amsterdam, v. 21, n. 2, p. 123-128, 1983. 
FILGUEIRA, F. A. R. Novo manual de olericultura: agrotecnologia moderna na produção e comercialização de hortaliças. Viçosa: UFV, 2000. 402 p.

FILGUEIRA, F. A. R. Novo manual de olericultura: agrotecnologia moderna na produção e comercialização de hortaliças. 2. ed. rev. e ampl. Viçosa: UFV, 2003. 412 p.

GODOY, H.; CORREA, A. R.; SANTOS, D. Clima do Paraná In: IAPAR. Manual agropecuário para o Paraná. Londrina, 1976. p. 16-37.

KATAYAMA, M. Nutrição e adubação de alface, chicória e almeirão. In: SIMPÓSIO SOBRE NUTRIÇÃO E ADUBAÇÃO DE HORTALIÇAS, 1990, Jaboticabal. Anais... Piracicaba: Potafós, 1993. cap. 4, p. 141-148.

MAROTO, J. V. Horticultura herbácea especial. 4. ed. Madri: Mundi, 1995. 611 p.

OKIMURA, M.; HANADA, T. The effect of mulching and row covers on vegetable production. JARQ, Tokio, v. 26, p. 294-303, 1993.

OTTO, R. F. Cubiertas de agrotextil en especies hortícolas: balances térmicos, evapotranspiracion y respuestas productivas. 1997. 157 f. Tesis (Doctoral) - Universidad de Córdoba, Córdoba, 1997.

OTTO, R. F.; REGHIN, M. Y.; SÁ, G. D. Utilização do 'não tecido' de polipropileno como proteção da cultura da alface durante o inverno de Ponta Grossa - PR. Horticultura Brasileira, Brasília, v. 19, n. 1, p. 49-52, 2001.

OTTO, R. F.; REGHIN, M. Y.; TIMÓTEO, P.; PEREIRA, A. V.; MADUREIRA, A. Eficiência do "não tecido" de polipropileno na proteção contra danos de geada na cultura do morangueiro, no município de Ponta Grossa - PR.
Horticultura Brasileira, Brasília, v. 18, p. 208-209, jul. 2000. Suplemento.

PEREIRA, A. V.; OTTO, R. F.; REGHIN, M. Y. Respostas do feijão-vagem cultivado sob proteção com agrotêxtil em duas densidades de plantas. Horticultura Brasileira, Brasília, v. 21, n. 3, p. 564-569, jul./set. 2003.

REGHIN, M. Y.; OTTO, R. F.; DUDA, C.; PADILHA, J. M.; TUPICH, F. L. B. Produção de alface com cobertura do solo e proteção das plantas com "não tecido" de polipropileno. Horticultura Brasileira, Brasília, v. 19, jul. 2001. Suplemento. CD-ROM.

REGHIN, M. Y.; OTTO, R. F.; PRIA, M. D.; FELTRIM, A. L.; VINNE, J. van der. Uso da cobertura de solo e da proteção das plantas na produção de rúcula. Horticultura Brasileira, Brasília, v. 20, n. 2, jul. 2002a. Suplemento.

REGHIN, M. Y.; OTTO, R. F.; VINNE, J. V. der; FELTRIN, A. L. Produção de pak choi sob proteção com "não tecido" de polipropileno. Horticultura Brasileira, Brasília, v. 20, n. 2, p. 233-236, jun. 2002 b.

RICIERI, R. P.; ESCOBEDO, J. F. Radiação solar global e difusa em estufas túneis com cobertura de polietileno. Energia na Agricultura, Botucatu, v. 11, n. 1, p. 15-37, 1996.

ROBLEDO, P. F.; MARTIN, L. V. Aplicación de los plásticos en la agricultura. Madrid: Mundi, 1981. 553 p.

SAURE, M. C. Causes of tip burn disorder in leaves of vegetables. Scientia Horticulturae, Amsterdam, v. 76, p. 131-147, 1998.

STRECK, N. A.; BURIOL, G. A.; ANDRIOLO, J. L. Crescimento da alface em túneis baixos com filme de polietileno perfurado. Ciência Rural, Santa Maria, v. 24, n. 2, p. 235-240, 1994. 